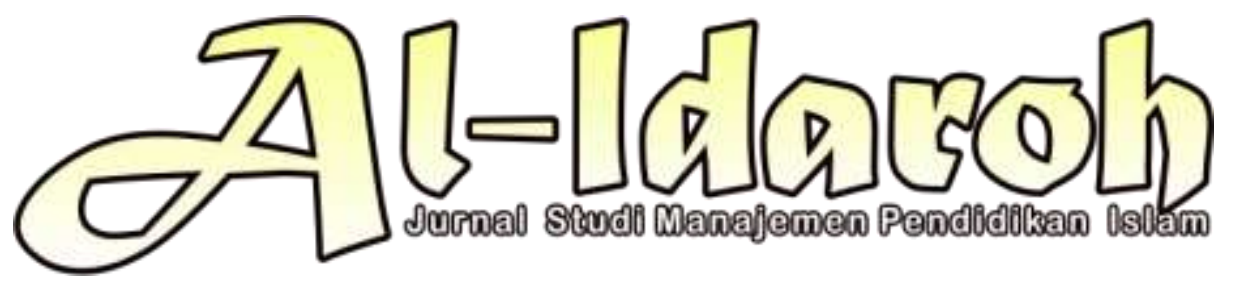

\title{
POLA KOMUNIKASI KETUA JURUSAN MANAJEMEN PENDIDIKAN ISLAM FITK UIN SUNAN KALIJAGA
}

\author{
Riyan \\ SD Negeri Trans Pendingan \\ Email: riyanjp13@gmail.com \\ Erlina Yuliyati \\ Universitas Islam Negeri Sunan Kalijaga \\ Email: yuliyatierlina@gmail.com
}

\begin{abstract}
As social beings, humans always communicate. The communication made by the head of the department is a strategy in managing the course of the organization so that it runs as expected. V arious impacts will arise if in an organization, including education, when there is miscommunication, including errors in decision making, the interruption does not reach the communicant, and there is no feedback. This research method uses qualitative types and data is obtained through interviews. The results of the study were (1) the communication pattern used by the head of the Department of Islamic Education Management at FITK UIN Sunan Kalijaga was a non-formal form. (2) Constraints in communication usually occur misunderstandings from both the communicator and the communicant, because it does not fit the situation and conditions. (3) Establishing communication with MPI throughout Indonesia through an organization called the MPI Study Program Communication Forum (FKPS MPI) and the Islamic Education Management Study Program Association (PPMPI).
\end{abstract}

Keywords: Communicator, Communicant and Message. 


\section{Pendahuluan}

Seluruh makhluk di jagat raya melakukan komunikasi dengan makhluk lainnya. Begitu juga umat Islam juga melakukan komunikasi, komunikasi tersebut tidak hanya dengan makhluk di dunia ini akan tetapi juga berkomunikasi dengan sang pencipta. Kegiatan komunikasi dengan sang pencipta yang biasa dilakukan umat Islam adalah sholat, sesungguhnya sholat merupakan do'a dan pesan yang ingin disampaikan untuk memohon petunjuk dan hidayah. Peran dan fungsi komunikasi berpengaruh dalam kehidupan manusia, kita semua telah terbiasa berkomunikasi demi memenuhi keinginan sehari-hari. Tanpa adanya komunikasi, maka tidak adanya kehidupan di dunia ini. ${ }^{1}$ Contoh kecil saja, pesawat terbang tidak akan bisa melakukan perjalanan tanpa adanya komunikasi antara pilot pesawat dengan petugas pengontrol yang berada di darat (bandara). Bisa dibayangkan tanpa adanya komunikasi, apakah bisa pesawat terbang tanpa ada bantuan dari darat.

Komunikasi dalam bahasa Yunani yaitu communicare yang berarti komunikator memberikan message kepada komunikan, agar komunikan melakukan pesan sesuai dengan yang diharapkan oleh komunikator. Komunikasi merupakan sesuatu yang tidak dapat dipisahkan oleh aspek kehidupan. Karena semua gerak-gerik langkah kita sering dibarengi dengan komunikasi. Begitu juga organisasi pendidikan juga tidak lepas dari komunikasi antara pemimpin dengan bawahan dan sebaliknya. ${ }^{2}$ Seorang pemimpin memiliki bentuk dalam berkomunikasi dengan bawahannya, dan diharapkan komunikasi yang dilakukan secara efektif. Adapun elemen-elemen komunikasi adalah pengirim pesan (komunikator), penerima pesan (komunikan), pesan yang disampaikan, media, dan feedback. ${ }^{3}$

Sebuah organisasi dalam pendidikan secara umum melakukan aktivitas, di dalamnya terdapat antara atasan dan bawahan melakukan komunikasi yang berisi perintah, intruksi dan pesan. Dengan adanya perintah, intruksi dan pesan membuat seluruh elemen organisasi bekerja demi tercapainya tujuan-tujuan yang diiinginkan. Elemen-elemen komunikasi adalah pengirim pesan, penerima pesan, pesan, tujuan,

${ }^{1}$ Brent D. Ruben dan Lea P. Stewart, Komunikasi dan Perilaku Manusia, Terj. Ibnu Hamid, (Jakarta: PT Rajagrafindo Persada, 2014), X.

${ }^{2}$ Ramlani Lina Sinaulan, "Komunikasi Terapeutik dalam Perspektif Islam," Jurnal Komunikasi Islam Vol. 6, no. 1 (2016), 132.

${ }^{3}$ Eni Fariyatul Fahyuni, Teknologi Informasi dan Komunikasi, (Sidoarjo: Umsida Press, 2017), 17. 


\section{Pola Komunikasi Ketua Jurusan Manajemen Pendidikan Islam FITK UIN Sunan Kalijaga}

media, gangguan dan umpan balik. Komunikasi yang dilakukan antara pemberi pesan dan penerima pesan menggunakan sarana/media berharap pesan yang diterima dapat dijalankan sesuai dengan tujuan dan memeberikan timbal balik tanpa adanya gangguan. ${ }^{4}$

Pemimpin organisasi sebagai atasan menjadi juru bicara dalam organisasi, sehingga pemimpin dituntut menjadi komunikator yang efektif. Komunikasi pada hakikatnya memindahkan sebuah pesan dari pemberi pesan kepada penerima pesan dengan tujuan memberikan timbal balik sesuai yang diharapkan pemberi pesan tanpa adanya gangguan dan kesalahpahaman. Pesan pada dasarnya berisikan pelajaran, perintah, pengarahan, nasihat dan informasi. ${ }^{5}$ Pemimpin yang mampu berkomunikasi dengan baik dan positif akan menghasilkan hasil yang baik dan positif pula. Secara umum fungsi komunikasi adalah untuk memberikan informasi, meyakinkan lawan bicara, mendidik dan menghibur. ${ }^{6}$

Dalam hal ini, fokus peneliti mengkaji pola komunikasi Ketua Jurusan Manajemen Pendidikan Islam (MPI) S1 FITK UIN Sunan Kalijaga. Bagaimana ketua jurusan MPI berkomunikasi dengan atasan maupun bawahan. Apa kendala komunikasi yang dihadapi ketua jurusan MPI selama menjabat. Bagaimana komunikasi dengan PPMPI Se-Indonesia. Pemimpin jurusan pastinya memiliki tanggung jawab yang lebih dalam menunjang suatu tujuan yang sesuai dengan visi misi UIN Sunan Kalijaga.

\section{Metode Penelitian}

Dalam penelitian ini, metode penelitian yang digunakan adalah kualitatif. Ada beberapa ahli yang menjelaskan tentang metode penelitian kualitatif, diantaranya adalah Moleong, yang menjelaskan bahwa metode peneitian kualitatif merupakan metode penelitian ilmiah yang bertujuan untuk memahami suatu fenomena sosial dengan mengedepankan proses interaksi dan komunikasi yang mendalam antara peneliti dengan fenomena yang diteliti. ${ }^{7}$

${ }^{4}$ Tikno Lensufiie, Leadership untuk Profesional dan Mahasiswa, (Jakarta: Erlangga, 2010), 182. ${ }^{5}$ Sondang P. Siagian, Teori dan Praktik Kepemimpinan, (Jakarta: PT Rineka Cipta, 2010), 56. ${ }^{6}$ Tikno Lensufiie, Leadership untuk Profesional dan Mahasiswa, (Jakarta: Erlangga, 2010), 178.

${ }^{7}$ Lexy J. Moleong, Metode Penelitian Kualitatif (Bandung: Remaja Rosda Karya, 2012), 6. 
Lokasi penelitian ini dilakukan di Jurusan Manajemen Pendidikan Islam FITK UIN Sunan Kalijaga Yogyakarta. Pengumpulan data diperoleh melalui wawancara dengan Ketua Jurusan Manajemen Pendidikan Islam yaitu Dr. Imam Machali, M.Pd, kemudian data dianalisis dan disajikan secara naratif.

\section{Pembahsan}

\section{A. Konsep dan Unsur-Unsur Komunikasi}

Seorang pemimpin menjadi pusat kekuatan bagi organisasi, pemimpin dituntut dapat berkomunikasi dengan seluruh pihak, baik melalui hubungan resmi maupun tidak resmi. Tujuan organisasi tercapai dengan baik dan sukses sebagian besar ditentukan oleh kecakapan pemimpin dalam berkomunikasi secara efektif dan efisien sehingga mudah dipahami oleh pihak lain. Maksudnya efektif disini adalah adanya pengaruh, kesan pemimpin kepada bawahannya serta para bawahan mampu mengerjakan sesuai perintah pimpinan. Komunikasi merupakan salah satu bagian psikologi yang membahas komunikasi dalam segala aspek seperti manusia, mekanik dan kelembagaan.

Komunikasi berasal dari bahasa latin "communis" yang berarti menyamakan perspektif antara dua orang atau lebih. Akar kata "communis" yaitu communico yang berarti berbagi. Berbagai disini adalah pemahaman bersama melalui pertukaran pesan dan informasi. ${ }^{8}$ C.P. Chaplin memberikan pengertian komunikasi adalah proses pengiriman informasi dari satu posisi ke posisi lain dan proses penerimaan tanda, simbol dan pesan.' Dikutip dari Ramlani Lina Sinaulan, Burce ddk mengartikan komunikasi adalah sebuah proses pengiriman dan penerimaan informasi. Haffied Cangara memaparkan bahwa komunikasi adalah bentuk interaksi dan hubungan sesama manusia untuk saling pengaruh mempengaruhi pihak satu dengan pihak lainnya tanpa ada gangguan dari pihak manapun. ${ }^{10}$

Dengan demikian, dapat dipahami bahwa komunikasi merupakan pesan, intruksi dan pengarahan dari komunikator (pemberi pesan) kepada komunikan melalui media agar dijalankan sesuai dengan keinginan pemberi pesan tanpa

${ }^{8}$ Nurani Soyomukti, Pengantar Ilmu Komunikasi, (Yogyakarta: Ar Ruzz Media, 2010), 55.

${ }^{9}$ Kartini Kartono, Pemimpin dan Kepemimpinan, (Jakarta: PT Rajagrafindo Persada, 2016), 134.

${ }^{10}$ Ramlani Lina Sinaulan, "Komunikasi Terapeutik dalam Perspektif Islam," Jurnal Komunikasi Islam Vol. 6, no. 1 (2016), 131. 


\section{Pola Komunikasi Ketua Jurusan Manajemen Pendidikan Islam FITK UIN Sunan Kalijaga}

adanya gangguan. Terbentuknya pola komunikasi dan budaya organisasi tergantung dari cara komunikasi pimpinan dalam organisasi. Hal tersebut, sebagaimana penjelasan Imam Machali selaku Ketua jurusan Manajemen Pendidikan Islam FITK UIN Sunan Kalijaga sebagai berikut:

Komunikasi antara dekan dengan kepala jurusan Fakultas Ilmu Tarbiyah dan Keguruan bersifat nonformal, dan memiliki prinsip kolegial. Dengan sifat ini tidak ada diskriminasi antara atasan dan bawahan sehingga membuat budaya kerja menjadi baik. ${ }^{11}$

\section{B. Proses, Tipe, Bentuk dan Persyaratan Komunikasi}

Seseorang menjadi bijak bila memiliki waktu luang dan memikirkan kejadian-kejadian dan pengalaman yang dihadapinya. Kebijaksanaan yang dimiliki seseorang seperti visi/tujuan yang dimiliki seorang pemimpin yang harus dibicarakan/diutarakan/dikomunikasikan/didiskusikan kepada seluruh elemen organisasi. Sehingga fungsi komunikasi antara pemimpin dengan warga organisasi dapat diklasifikasikan yaitu to inform, to persuade, to educate dan to entertaint. $^{12}$

Proses komunikasi tidaklah gampang untuk dilakukan, seorang yang memberikan pesan harus memahami psikologi tentang diri sendiri dan juga yang menerima pesan. Sepertinya berkomunikasi sangat rumit jika harus memahami tentang psikologi. Akan tetapi pemahaman tentang psikologi sangat diperlukan karena manusia sebagai komunikator memiliki perilaku alamiah. ${ }^{13}$ Proses komunikasi terbagi dua menjadi primer dan sekunder. Proses komunikasi primer adalah proses penyampaian informasi kepada pihak lain dengan menggunakan lambang (bahasa, gesture dan isyarat) secara langsung dapat menerjemahkan maksud dan tujuan komunikator kepada komunikan. Proses komunikasi sekunder adalah komunikator menyampaikan pesan dan informasi kepada komunikan dengan melalui media sarana kedua. Proses ini terjadi pihak komunikator dan komunikan berjarak jauh. ${ }^{14}$

\footnotetext{
${ }^{11}$ Wawancara dengan Ketua Jurusan MPI FITK UIN Sunan Kalijaga, pada Tanggal 18 September 2019, Pukul 10.30 wib.

12Tikno Lensufiie, Leadership untuk Profesional dan Mahasiswa, (Jakarta: Erlangga, 2010), 178.

${ }^{13}$ Tikno Lensufiie, Leadership untuk Profesional dan Mahasiswa, (Jakarta: Erlangga, 2010), 182.

${ }^{14}$ Onong Uchjana Effendy, Ilmu Komunikasi Teori dan Praktek, (Bandung: Remaja Karya, 1986), 11-16.
} 
Tipe komunikasi berdasarkan pengungkapan terbagi menjadi dua, secara lisan dan tertulis (verbal) dan secara isyarat, simbol dan lambang (nonverbal). ${ }^{15}$ Komunikasi verbal adalah komunikasi yang memakai bahasa, baik bahasa tulis maupun bahasa lisan. Kemudiaan komunikasi nonverbal yaitu komunikasi menggunakan simbol, isyarat, gambar, logo/lambang dan mimik wajah. ${ }^{16}$ Dalam sebuah komunikasi secara lisan (verbal), ada beberapa hal yang perlu diperhatikan yaitu kata-kata yang keluar dari mulut, intonasi dan nada suara, bahasa/gerakan tubuh dan pemahaman dari pesan yang disampaikan kepada penerima pesan. ${ }^{17}$

Bentuk komunikasi terjadi dapat dikelompokkan berdasarkan jumlah lawan bicara yang terlibat dalam komunikasi. Bentuk komunikasi terbagi yaitu pertama, intrapribadi adalah komunikasi yang berlangsung dengan diri sendiri. Kedua, antarpribadi adalah komunikasi dengan beberapa orang dengan tujuan mendapat respon seketika. Ketiga, komunikasi publik adalah komunikasi yang berlangsung satu atau dua lebih pembicara dengan beberapa audien atauu penerima pesan seperti ceramah, pidato dan seminar. Keempat, komunikasi organisasi adalah komunikasi yang terjadi antara pimpinan dan bawahan yang akan memberikan keuntungan pada sebuah organisasi. Kelima, komunikasi masa adalah komunikasi yang dilakukan beberapa orang atau tokoh untuk mendapatkan sebuah dukungan seperti kampanye. ${ }^{18}$

Syarat komunikasi yaitu Pertama, bersifat terbuka dalam suasana tidak terhalang dan tidak ada tekanan oleh apapun, Kedua, pemimpin menghormati prestasi bawahan/orang lain dan memaafkan kekurangan/kesalahan bawahannya, Ketiga, pemimpin bersedia menerima pendapat orang lain tanpa ada rasa curiga dan mampu merasakan kehidupan orang lain. ${ }^{19}$ Begitu juga di Jurusan Manajemen Pendidikan Islam FITK UIN Sunan Kalijaga, suasana kolegial yang sudah menjadi budaya dalam organisasi tidak lagi ada tekanan dari atasan.

\footnotetext{
${ }^{15}$ Muh. Syawir Dahlan, "Etika Komunikasi dalam Al-Qur'an dan Hadis”, Jurnal Dakwah Tabligh vol. 15, no. 1 (2014), 116.

${ }^{16}$ Eni Fariyatul Fahyuni, Teknologi Informasi dan Komunikasi, (Sidoarjo: Umsida Press, 2017), 16.

${ }^{17}$ Tikno Lensufiie, Leadership untuk Profesional dan Mahasiswa, (Jakarta: Erlangga, 2010), 191.

${ }^{18}$ Syaiful Rohim, Teori Komunikasi: Perspektif, Ragam dan Aplikasi, (Jakarta: Rineka Cipta, 2009), 17-20.

${ }^{19}$ Kartini Kartono, Pemimpin dan Kepemimpinan, (Jakarta: PT Rajagrafindo Persada, 2016), 137-139.
} 


\section{Pola Komunikasi Ketua Jurusan Manajemen Pendidikan Islam FITK UIN Sunan Kalijaga}

Tercapainya sebuah tujuan merupakan kesuksesan dalam berkomunikasi, semua itu tidak terlepas dari keefektifan antara komunikator dengan komunikan. Zikri dan Ahmad menjelaskan, bahwa komunikasi dikatakan efektif apabila pesan yang disampaikan oleh komunikator efek atau perubahan sebagaimana yang diharapkan komunikator. Perubahan tersebut dapat dilihat melalui tanggapan yang diberikan komunikan sebagai feedback.. ${ }^{20}$ Penjelasan tersebut, senada dengan uraian Nisa, yang menjelaskan bahwa komunikasi berlangsung secara efektif jika terdapat aliran informasi dua arah antara komunikator dan komunikan serta informasi tersebut sama-sama direspon sesuai harapan kedua pelaku komunikasi. ${ }^{21}$

Dalam komunikasi pastinya banyak melibatkan unsur-unsur komunikasi yaitu pertama, pemberi informasi (komunikator) proses komunikasi diawali oleh pengirim pesan yang memiliki gagasan, ide atau pikiran, kemudian disampaikan kepada pihak penerima pesan. Pemberi pesan disebut juga dengan "komunikator". Komunikator bisa jadi adalah individu, kelompok atau organisasi. Kedua, penerima informasi (komunikan) merupakan sasaran dari pesan. Ketiga, pesan (message) yang dapat dirasakan atau diterima pancaindrera. Keempat, media adalah jalan yang digunakan komunikator untuk sampainya pesan kepada komunikan. Kelima, gangguan merupakan salah satu unsur yang masuk dalam komunikasi karena pasti adanya yang menghalangi sampainya pesan kepada sasaran. Gangguan bisa saja terjadi oleh komunikator, komunikan dan salah pemilihan kata pesan. Keenam, Umpan balik tujuan akhir dari pesan dan informasi yang diharapkan oleh pengirim pesan. ${ }^{22}$ Di Fakultas Ilmu Tarbiyah dan Keguruan tidak luput dari kesalahan dalam berkomunikasi, sebagaimana yang telah disampaikan Imam Machali, bahwa:

Salah komunikasi dalam organisasi pendidikan itu pasti terjadi, biasanya di Fakultas tarbiyah kesalahan komunikasi terjadi karena kesalahan dan ketidaksesuaian waktu dan kondisi dari

\footnotetext{
${ }^{20}$ Zikri Fachrul Nurhadi dan Achmad Wildan Kurniawan, “ Kajian Tentang Efektifitas Pesan dalam Komunikasi”, Jurnal Komunikasi, Vol. 3 No. 1(2017), 91.

${ }^{21}$ Hoirun Nisa, “ Komunikasi yang Efektif dalam Pendidikan Karakter”, Universum, Vol. 10, No. 1 (2016), 61.

${ }^{22}$ Morissan, Teori Komunikasi tentang Komunikator, Pesan, Percakapan, dan Hubungan, (Bogor: Ghalia Indonesia, 2009), 17-22.
} 
komunikator/atasan. Dan tidak dipungkiri juga kesalahan dalam berkomunikasi terjadi karena kesalahpahaman komunikan dalam menerima pesan. Contoh pada waktu Ujian Tengah Semester, kemudian atasan membahas masalah perkuliahan yang sedang berjalan sehingga terjadi kesalahpahaman antara atasan dan bawahan. ${ }^{23}$

\section{Faktor yang Mempengaruhi Kelancaran dan Hambatan Komunikasi}

Pada dasarnya faktor yang dapat mempengaruhi Kelancaran komunikasi sangatlah banyak akan tetapi disini akan dipaparkan sedikit faktornya yaitu, pertama faktor intellegensi, seorang yang memiliki intellegensi tinggi lebih banyak penguasaan kata dibandingkan intellegensi rendah. Kedua, faktor budaya dan bahasa sangat berpengaruh terhadap kelancaran berkomunikasi. Ketiga, faktor pengalaman dan kepribadian seseorang dapat juga mempengaruhi kelancaran dalam berkomunikasi. Kemudian hasil wawancara dengan kepala jurusan Manajemen Pendidikan Islam FITK UIN Sunan Kalijaga mengenai faktor kelancaran komunikasi adalah kesiapan komunikator, sesuai situasi dan kondisi dan psikologi orang lain.

Hambatan komunikasi bisa saja terjadi dari semua unsur-unsur komunikasi. Pertama, hambatan komunikator misal pesan yang hendak dikirim belum jelas bagi dirinya. Hal ini dipengaruhi oleh perasaan situasi emosional sehingga berdampak motivasi, yaitu memberikan peluang kepada seseorang bertindak sesuai kebutuhan dan keinginan. Kedua, hambatan dalam simbol. Hal ini terjadi karena bahasa yang digunakan antara komunikator dan komunikan tidak sesuai dengan kondisi. Ketiga, hambatan media, hambatan terjadi saat penggunaan media komunikasi, misalkan gangguan suara radio sehingga tidak dapat menerima pesan secara jelas. Keempat, hambatan dalam bahasa sandi, hambatan kesalahpahaman komunikan dalam menafsirkan sandi. Kelima, hambatan dari komunikan, contoh kurangnya perhatian pada saat menerima pesan, sikap prasangka tanggapan yang salah dan tidak konfirmasi lebih lanjut. ${ }^{24}$

${ }^{23}$ Wawancara dengan Ketua Jurusan MPI FITK UIN Sunan Kalijaga, pada Tanggal 18 September 2019, Pukul 10.30 wib.

${ }^{24}$ Siti Rahma Nurdianti, "Analisis Faktor-Faktor Hambatan Komunikasi dalam Sosialisasi Program Keluarga Berencana pada Masyarakat Kebon Agung Samarinda”, E-Jurnal Ilmu Komunikasi 2, no. 2 (2014), 149. 


\section{Pola Komunikasi Ketua Jurusan Manajemen Pendidikan Islam FITK UIN Sunan Kalijaga}

\section{D.Pendekatan Komunikasi dan Implementasinya dalam Kepemimpinan Pendidikan Islam}

Organisasi kata yang sudah tidak asing lagi bagi kita, bahkan hampir semua kegiatan yang dilakukan dalam organisasi baik di sekolah, pada masa kuliah dan tempat bekerja. Kita masuk berbagai macam organisasi untuk memenuhi kebutuhan, fisik, psikologis, sosial, politik, spiritual dan ekonomi. Dalam organisasi, komunikasi berperan penting karena tanpa komunikasi tidak akan terjadi koordinasi antara atasan dan bawahan. ${ }^{25}$ Komunikasi dalam Islam sebagaimana terkandung dalam Al-Qur'an surat An-Nisa' ayat 63, berikut:

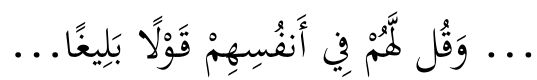

Artinya: ... Dan katakanlah kepada mereka perkataan yang berbekas pada jiwa mereka... (Q.S An-Nisa 4:63)

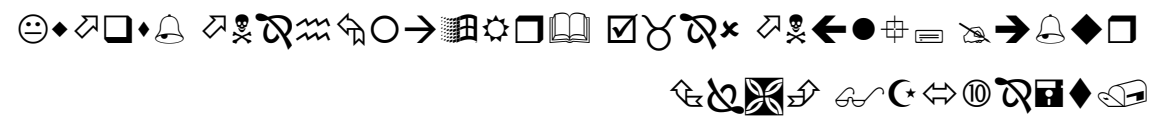

Artinya: dan Katakanlah kepada mereka Perkataan yang berbekas pada jiwa mereka.

Kata Balighan pada ayat tersebut terdiri dari huruf ba', lam, dan ghain. Para pakar bahasa menyatakan bahwa huruf-huruf dalam kata tersebut mengandung arti sampainya sesuatu ke sesuatu yang lain, juga dapat bermakna cukup, karena kecukupan mengandung arti sampainya sesuatu kepada batas yang dibutuhkan. ${ }^{26}$ Lebih lanjut, Shihab menjelaskan beberapa kriteria sehingga pesan yang disampaikan dapat disebut balighan, yaitu: ${ }^{27}$

1. Tertampungnya seluruh pesan dalam kalimat yang disampaikan.

2. Kosakata yang digunakan tidak asing bagi pendengarnya

3. Kalimat yang digunakan tidak bertele-tele, tapi tidak pula singkat sehingga mengaburkan pesan.

4. Kesesuaian kandungan dan gaya bahasa dengan lawan bicara.

\footnotetext{
${ }^{25}$ Brent D. Ruben dan Lea P. Stewart, Komunikasi dan Perilaku Manusia, Terj. Ibnu Hamid, (Jakarta: PT Rajagrafindo Persada, 2014), 325.

${ }^{26}$ M.Quraish Shihab, Tafsir Al-Misbah: Pesan, Kesan, dan Keserasian Al-Qur'an, Jilid 2 (Jakarta: Lentera Hati. 2002), 426.

${ }^{27}$ M.Quraish Shihab, Tafsir Al-Misbah: Pesan, Kesan, dan Keserasian Al-Qur'an, Jilid 2 (Jakarta: Lentera Hati. 2002), 596.
} 
5. Kesesuaian dengan tata bahasa.

Dengan demikian, qaulan balighan dapat diartikan dengan ucapan yang sampai pada tujuan pembicara, dengan ungkapan yang tepat, efektif, sehingga sampai pada lawan bicara. Seseorang dalam menyampaikan pesan harus sesuai dengan tujuan yang ingin dicapai sehingga akan tercipta budaya saling percaya antara atasan dan bawahan.

Ami Muhammad menjelaskan bahwa komunikasi dalam organisasi dapat di identifikasi melalui 3 pendekatan, pertama pendekatan makro. Pendekatan ini organisasi dianggap sebagai struktur besar yang berinteraksi dengan lingkungannya. Dalam interaksi tersebut organisasi melakukan aktivitas seperti memproses lingkungan, mengadakan identifikasi, melakukan integrasi dan menentukan tujuan organisasi. Kedua, pendekatan mikro. Pendekatan mikro menitikberatkan kepada komunikasi dalam unit dan bagian unit pada suatu organisasi. Komunikasi yang yang diperlukan adalah komunikasi antara anggota kelompok, komunikasi melibatkan anggota kelompok dalam tugas kelompok, dan komunikasi untuk menjaga budaya organisasi. Ketiga, pendekatan individual. Pendekatan ini berpusat kepada tingkah laku komunikasi individual dalam organisasi. Seluruh tugas-tugas yang diuraikan pada kedua pendekatan yang terdahulu akhirnya diselesaikan oleh komunikasi individual satu sama lainnya. ${ }^{28}$

Kunci dari seluruh aktivitas adalah komunikasi. Pendekatan komunikasi di Fakultas Ilmu Tarbiyah dan Keguruan UIN Sunan Kalijaga dengan menggunakan pendekatan mikro, dimana atasan dan bawahan bekerja secara kolegial. Sehingga budaya yang ditimbulkan non formal, kerjasama antara Dekan dengan para ketua jurusan seperti teman sejawat tetapi tetap ada saling menghormati. Komunikasi sebuah ilmu seni, bagaimana seorang pemimpin dapat menyampaikan pesan dengan baik sehingga penerima pesan dapat menerima dan memberikan feedback kepada pemberi pesan.

Cara kerja menyampaikan dan meneruskan intruksi merupakan kegiatan komunikasi dan timbal balik yang dilakukan komunikator dan komunikan. Agar terjadi perubahan dalam organisasi adanya cara kerjasama yaitu menyampaikan

${ }^{28}$ Arni Muhammad, Komunikasi Organisasi, (Jakarta: Bumi Aksara, 2017), 74-80. 


\section{Pola Komunikasi Ketua Jurusan Manajemen Pendidikan Islam FITK UIN Sunan Kalijaga}

dan meneruskan pesan yang telah diterima. ${ }^{29}$ Anggota kelompok organisasi bekerja sama untuk mencapai tujuan organisasi. Hal tersebut sebagaimana yang dilakukan ketua jurusan MPI FITK UIN Sunan Kalijaga dengan PPMPI yang terdiri dari ketua dan sekretaris jurusan MPI Se-Indonesia, seperti mengadakan kegiatan webinar, prosiding, dan sebagainya.

Saluran komunikasi berbagai macam cara, agar dapat dipahami oleh penerima pesan. Bentuk saluran komunikasi dapat berupa kertas tulis (tertulis atau dicetak), telepon, internet radio dan televisi. ${ }^{30}$ Komunikasi tidak hanya pesan lewan lisan akan tetapi juga dengan tulisan. Implementasi komunikasi dalam pendidikan Islam yang dilakukan Imam Machali selaku ketua jurusan adalah melakukaan penulisan karya ilmiah seperti jurnal, pembuatan buku prosiding (kontribusi yang dihasilkan peneliti dalam seminar).

Komunikasi efektif dapat terjadi jika hubungan atasan dan bawahan dibangun budaya berdasarkan kepercayaan dan suasana organisasi yang positif. Faktor kepemimpinan dan komunikasi dalam organisasi adalah dua faktor penting dalam membangun budaya organisasi yang dapat memfasilitasi, memberikan dan mengayomi sekaligus menambah wawasan pengetahuan kepada bawahan dalam menjalankan tugas-tugas dan dapat menumbuhkan optimisme pada bawahan itu sendiri. ${ }^{31}$

Komunikasi yang baik dan efektif juga dibangun rasa saling percaya antara atasan dan bawahan, karena rasa percaya sebuah modal untuk membangun sebuah komitmen dalam bekerja sama. Dalam implementasi komunikasi kepala jurusan Manajemen Pendidikan Islam FITK UIN Sunan Kalijaga Khususnya dengan sistem budaya non formal dan kolegial. Maksudnya adalah agar tidak terjadi kesenjangan antara atasan dan bawahan komunikasi dalam mengambil keputusan dan kebijakan semuanya berpijak kepada kebersamaan. Terkadang juga terjadi gangguan dalam berkomunikasi yang disebabkan oleh pesan yang disampaikan

\footnotetext{
${ }^{29}$ D. Lawrence Kincaid dan Wilbur Schramm, Asas-Asas Komunikasi antar Manusia, Terj Agus Setiadi, (Jakarta: LP3ES, 1981), 125.

${ }^{30}$ Aida Vitayala S. Hubeis, Dkk., Komunikasi Ivovasi, (Jakarta: Universitas Terbuka, 2010), 4.3.

${ }^{31}$ Agus Yudi Harsono, Supratomo, Muhammad Farid, “Analisis Gaya Kepemimpinan dan Komunikasi Organisasi Antara Atasan-Bawahan dalam Membangun Budaya Organisasi Di Lingkungan Sekretariat Dprd Kota Bengkulu,” Jurnal Komunikasi KAREBA 4, no.3 (2015), 330.
} 
komunikator yang tidak sesuai waktu sehingga membuat komunikan salah paham dalam merespon pesan tersebut. Contohnya dalam situasi kondisi UTS (Ujian Tengah Semester) tetapi pesan yang disampaikan komunikator mengenai perkuliahan yang sedang berjalan, ujar Imam Machali selaku Kepala Jurusan Manajemen Pendidikan Islam.

\section{Kesimpulan}

Komunikasi merupakan kebutuhan penting dalam kehidupan sosial. MPI, sebagai lembaga pendidikan tentunya tidak lepas dari kegiatan komunikasi, baik komunikasi yang dilakukan ketua jurusan dengan atasan, ketua jurusan dengan mahasiswa, ketua jurusan dengan anggotanya, ketua jurusan dengan stakeholder dan sebagainya. Pola komunikasi yang digunakan oleh ketua jurusan MPI FITK UIN Sunan Kalijaga adalah komunikasi non formal. Adapun kendala yang dihadapi dalam komunikasi adalah terjadinya kesalahpahaman baik dari komunikator atau komunikan yang disebabkan oleh situasi dan kondisi.

\section{Daftar Rujukan}

Aida Vitayala S. Hubeis., Dkk. Komunikasi Ivovasi. Jakarta: Universitas Terbuka, 2010.

Dahlan, Muh. Syawir. "Etika Komunikasi dalam Al-Qur'an dan Hadis," Jurnal Dakwah Tabligh, Vol. 15, No. 1, 2014.

Effendy, Onong Uchjana. Ilmu Komunikasi Teori dan Praktek. Bandung: Remaja Karya, 1986.

Fahyuni, Eni Fariyatul. Teknologi Informasi dan Komunikasi. Sidoarjo: Umsida Press, 2017.

Harsono, Agus Yudi., dkk. "Analisis Gaya Kepemimpinan dan Komunikasi Organisasi Antara Atasan-Bawahan dalam Membangun Budaya Organisasi Di Lingkungan Sekretariat Dprd Kota Bengkulu,' Jurnal Komunikasi Kareba Vol. 4, No.3, 2015.

Kartono, Kartini. Pemimpin dan Kepemimpinan. Jakarta: PT Rajagrafindo Persada, 2016. 


\section{Pola Komunikasi Ketua Jurusan Manajemen Pendidikan Islam FITK UIN Sunan Kalijaga}

Kincaid, D. Lawrence dan Wilbur Schramm. Asas-Asas Komunikasi antar Manusia, Terj Agus Setiadi. Jakarta: LP3ES, 1981.

Lensufiie, Tikno. Leadership untuk Profesional dan Mahasiswa. Jakarta: Erlangga, 2010.

Moleong, Lexy J. Metode Penelitian Kualitatif. Bandung: Remaja Rosda Karya, 2012.

Morissan. Teori Komunikasi tentang Komunikator, Pesan, Percakapan, dan Hubungan. Bogor: Ghalia Indonesia, 2009.

Muhammad, Arni. Komunikasi Organisasi. Jakarta: Bumi Aksara, 2017.

Nisa, Hoirun. "Komunikasi yang Efektif dalam Pendidikan Karakter," Universum, Vol. 10, No. 1, 2016.

Nurdianti, Siti Rahma. "Analisis Faktor-Faktor Hambatan Komunikasi dalam Sosialisasi Program Keluarga Berencana pada Masyarakat Kebon Agung Samarinda”, E-Jurnal Ilmu Komunikasi, Vol. 2, No. 2, 2014.

Nurhadi, Zikri Fachrul. dan Kurniawan, Achmad Wildan. "Kajian Tentang Efektifitas Pesan dalam Komunikasi,” Jurnal Komunikasi, Vol. 3 No. 1, 2017

Rohim, Syaiful. Teori Komunikasi: Perspektif, Ragam dan Aplikasi. Jakarta: Rineka Cipta, 2009.

Ruben, Brent D. dan Stewart, Lea P. Komunikasi dan Perilaku Manusia, Terj. Ibnu Hamid. Jakarta: PT Rajagrafindo Persada, 2014.

Shihab, M. Quraish. Tafsir Al-Misbah: Pesan, Kesan, dan Keserasian Al-Qur'an, Jilid 2. Jakarta: Lentera Hati. 2002.

Siagian, Sondang P. Teori dan Praktik Kepemimpinan. Jakarta: PT Rineka Cipta, 2010 .

Sinaulan, Ramlani Lina. "Komunikasi Terapeutik dalam Perspektif Islam," Jurnal Komunikasi Islam, Vol. 6, No. 1, 2016.

Soyomukti, Nurani. Pengantar Ilmu Komunikasi. Yogyakarta: Ar Ruzz Media, 2010. 